\title{
A Comparison of Urology Training Across Five Major English-Speaking Countries
}

\author{
Rishi Naik ${ }^{\mathrm{a}} \quad$ Indrajeet Mandal ${ }^{\mathrm{a}} \quad$ Alexander Hampson $^{\mathrm{b}} \quad$ Rowan Casey $^{\mathrm{c}}$ Nikhil Vasdev $^{\mathrm{b}}$ \\ aUCL Medical School, Faculty of Medical Sciences, University College London, London; bDepartment of Urology, Lister Hospital, Stevenage; \\ 'Department of Urology, Colchester General Hospital, Colchester, UK
}

\author{
Key Words \\ Urology $\cdot$ Comparison $•$ International Medical Graduates • \\ Countries $\cdot$ Training
}

\section{Abstract}

Background: Urology is a rapidly evolving specialty, although wide variations exist between training programs in different countries. We aimed to compare the status of urology training in 5 English-speaking countries. Materials and Methods: Features compared include the training pathway structure, training requirements, competition levels and the process of moving country for international medical graduates. Results: Length of training varied considerably across countries, ranging from 5 years in the USA and Canada, to 7 years in Australia and New Zealand and 9 years in the UK. Ease of entering urology training for international medical graduates also varies, with the UK relatively easier compared to other countries. All countries encourage participation in research during training as well as completion of non-urology and urology specific surgical examinations. Conclusion: Following the Royal College of Surgeons Improving Surgical Training report, it is vital that the UK incorporates optimal elements of international programs in order to provide the best standards for trainees and world-class care in urology.

(C) 2020 The Author(s)

Published by S. Karger AG, Basel

\section{Introduction}

Urology remains one of the most rapidly evolving surgical specialties available. Since the first laparoscopic

\section{KARGER}

Fax +41613061234

E-Mail karger@karger.com

www.karger.com
(C) 2020 The Author(s)

Published by S. Karger AG, Basel Open access

This article is licensed under the Creative Commons AttributionNonCommercial-NoDerivatives 4.0 International License (CC BYNC-ND) (http://www.karger.com/Services/OpenAccessLicense). Usage and distribution for commercial purposes as well as any dis-
Usions tribution of modified material requires written permission. nephrectomy over 2 decades ago [1], the field has seen major technological advancements, including the increased use of pioneering robotic and laser assisted surgeries [2, 3]. In addition, urology offers a diverse breadth of subspecialties including andrology, urological oncology, reconstructive urology, pediatric urology and many more. In recent times we have seen an increase in the number of trainees opting for urology training and fellowship positions [4].

In this study we aimed to summarize the postgraduate training pathways for urology in major English-speaking countries, including the United Kingdom, United States of America, Canada, Australia and New Zealand. We assessed the training pathway, competition, training requirements, and the process of moving country. By highlighting the strengths and limitations of training in these countries, we hope this will inform prospective trainees and guide future changes to training pathways.

\section{Materials and Methods}

Data was collected from the literature, publicly available documents from official governing bodies and from online resources. Variables of interest included the structure and length of training pathways, the curricula for each program, number of procedures performed by trainees, examinations required, competition levels and the process for moving country.

\section{Results}

A summary of the career pathway in each country and key features are provided in tables 1 and 2 . 
Table 1. Outline of the typical career pathway in each country

\begin{tabular}{lllll}
\hline PGY & UK & USA & Canada & Australia and New Zealand \\
\hline 1 & FY1 & surgical intern & surgical foundations trainee & intern \\
2 & FY2 & urology resident & surgical foundations trainee & resident \\
3 & core surgical trainee (CT1) & urology resident & urology resident & urology registrar (nSET1) \\
4 & core surgical trainee (CT2) & urology resident & urology resident & urology registrar (nSET2) \\
5 & urology registrar (ST3) & urology resident (chief resident) & urology resident & urology registrar (nSET4) \\
6 & urology registrar (ST4) & & & urology registrar (nSET5) \\
7 & urology registrar (ST5) & & & \\
8 & urology registrar (ST6) & & & \\
9 & urology registrar (ST7) & & & \\
\hline
\end{tabular}

Table 2. A comparison of key features in each country

\begin{tabular}{|c|c|c|c|c|c|}
\hline & UK & USA & Canada & Australia & New Zealand \\
\hline Qualification body & GMC & $\mathrm{ABU}$ & $\begin{array}{l}\text { Royal College of Physicians } \\
\text { and Surgeons of Canada }\end{array}$ & RACS & RACS \\
\hline Qualification name & $\begin{array}{l}\text { Certificate of Completion } \\
\text { of Training in urology }\end{array}$ & $\begin{array}{l}\text { Board Certification in } \\
\text { urology }\end{array}$ & $\begin{array}{l}\text { Royal College Certification } \\
\text { in urology }\end{array}$ & FRACS (urology) & FRACS (urology) \\
\hline $\begin{array}{l}\text { Organization developing } \\
\text { curriculum }\end{array}$ & GMC & ACGME & $\begin{array}{l}\text { Royal College of Physicians } \\
\text { and Surgeons of Canada }\end{array}$ & USANZ & USANZ \\
\hline $\begin{array}{l}\text { Additional urology organi- } \\
\text { zations in the country }\end{array}$ & $\begin{array}{l}\text { British Association of } \\
\text { Urological Surgeons }\end{array}$ & $\begin{array}{l}\text { ABU, American Urological } \\
\text { Association }\end{array}$ & $\begin{array}{l}\text { Canadian Urological } \\
\text { Association }\end{array}$ & & \\
\hline $\begin{array}{l}\text { Number of practicing } \\
\text { urology consultants }\end{array}$ & $1,083(2017)[42]$ & 10,012 (2017) [14] & $716(2018)[43]$ & $380(2017)$ & $120(2017)$ \\
\hline $\begin{array}{l}\text { Minimum postgraduate } \\
\text { years of training }\end{array}$ & 9 & 5 & 5 & 7 & 7 \\
\hline $\begin{array}{l}\text { Years of other surgery } \\
\text { training (e.g. core surgical } \\
\text { training) }\end{array}$ & 2 & 1 & 2 & 1 & 1 \\
\hline Years of urology specific & 5 & 4 & 3 & 4 & 4 \\
\hline $\begin{array}{l}\text { Number of training posi- } \\
\text { tions per year }\end{array}$ & $47(2018)$ & 325 (2018) & $29(2018)$ & $\begin{array}{l}18 \text { (Australia and New } \\
\text { Zealand, 2018) }\end{array}$ & $\begin{array}{l}18 \text { (Australia and New } \\
\text { Zealand, 2018) }\end{array}$ \\
\hline $\begin{array}{l}\text { Exams not including } \\
\text { licencing exams }\end{array}$ & $\begin{array}{l}\text { membership of the RCS, } \\
\text { Fellowship of the RCS } \\
\text { (urology) }\end{array}$ & $\begin{array}{l}\text { Board Certification Exam } \\
\text { in Urology }\end{array}$ & $\begin{array}{l}\text { Surgical Foundations Exam } \\
\text { Certification Exam in } \\
\text { Urology }\end{array}$ & $\begin{array}{l}\text { Generic Surgical } \\
\text { Sciences Examination, } \\
\text { clinical examination, } \\
\text { FRACS (urology) }\end{array}$ & $\begin{array}{l}\text { Generic Surgical } \\
\text { Sciences Examination, } \\
\text { clinical examination, } \\
\text { FRACS (urology) }\end{array}$ \\
\hline Research requirements & $\begin{array}{l}\text { two first name papers or } \\
\text { equivalent }\end{array}$ & $\begin{array}{l}\text { involvement in scholarly } \\
\text { activity; research rotations } \\
\text { cannot exceed } 6 \text { months }\end{array}$ & $\begin{array}{l}\text { must complete } 1 \text { research or } \\
\text { educational project; research } \\
\text { rotations cannot exceed } 12 \\
\text { weeks }\end{array}$ & $\begin{array}{l}\text { must present or publish } \\
\text { a project, or spend } 6 \\
\text { months in full time } \\
\text { research }\end{array}$ & $\begin{array}{l}\text { must present or pub- } \\
\text { lish a project, or spend } \\
6 \text { months in full time } \\
\text { research }\end{array}$ \\
\hline $\begin{array}{l}\text { Time allowed for electives } \\
\text { or subspecialty of choice }\end{array}$ & varies between program & varies between program & $\begin{array}{l}\text { varies between programs; } \\
\text { max } 3 \text { months of elective or } \\
\text { research time }\end{array}$ & none specified & none specified \\
\hline $\begin{array}{l}\text { Minimum time spent as } \\
\text { chief resident/prep for } \\
\text { independent }\end{array}$ & see above & 12 months & 6 months & 12 months & 12 months \\
\hline Duty hours as a resident & maximum 48 per week & maximum 80 per week & $\begin{array}{l}\text { no limit; average } 56.8 \text { per } \\
\text { week (excl. on call) }\end{array}$ & $\begin{array}{l}\text { no limit; average } 49 \\
\text { [44] }\end{array}$ & $\begin{array}{l}\text { no limit; average } 49 \\
\text { [44] }\end{array}$ \\
\hline Trainee salary & $\begin{array}{l}£ 37,191(\mathrm{CT} 1-2) £ 47,132 \\
(\mathrm{ST} 3-7)[45]\end{array}$ & $\begin{array}{l}\text { US } \$ 57,000 \text { (average) } \\
\text { [46] }\end{array}$ & $\begin{array}{l}\$ 46,000-80,000 \\
\text { (range year } 1-5 \text {, varies by } \\
\text { state) [47] }\end{array}$ & $\begin{array}{l}\$ 110,000-136,000 \\
\text { (base salary range, year } \\
1-5)[48]\end{array}$ & \\
\hline
\end{tabular}

USANZ = Urological Society of Australia and New Zealand.

\section{United Kingdom}

Newly qualified graduates in the UK must complete one foundation year (FY1) in order to become fully registered with the General Medical Council (GMC), followed by FY2. Prior to beginning urology training, doctors must complete a 2-year Core Surgical Training (CST) program (CT1 and CT2), where trainees rotate through a range of surgical specialties, as well as their 
membership of the Royal College of Surgeons (RCS) examinations. Applicants wishing to pursue training of urology must complete 6 months in urology during their CST. Specialty training in urology takes a further 5 years (ST3-ST7), including completion of the fellowship of RCS urology examination. The final year (ST7) allows exposure to a chosen subspecialty. Completion of this training leads to the award of a certificate of completion of training, after which point a candidate can practice as an independent urologist [5]. Trainees can opt to pursue further training in the form of a post-certificate of completion of training fellowship, which is becoming increasingly common. Many trainees undertake fellowships abroad, with the USA and Australia being particularly popular destinations [4].

Surgical training in the UK is currently under review. Following the RCS 'Improving Surgical Training' initiative [6], urology will pilot a 'run-through' training scheme beginning August 2019, where, candidates will begin urology training after FY2, without the need to reapply. Skills formerly acquired through CST will be integrated into the early stages of run-through training. Positive results from the pilot could lead to a national rollout of the revised training program.

Competition for entry at CST and urology ST3 is high, with both increasing in recent years. In 2018, there were 2.94 applications per post for CST, and 2.66 applications per post at ST3. For 2016 and 2017, urology ST3 competition ratios were 2.16 and 2.15 applications per post respectively [7].

For CST several core competencies exist as set out by the Joint Committee on Surgical Training. This includes several areas such as work based assessments, continuing professional development courses, audits, a logbook of procedures, and an educational supervisor report [8].

For urology training, the Joint Committee on Surgical Training sets out further competencies required for certification, including exposure to urological subspecialties, 2 first author publications, evidence of audit, significant teaching experience and attendance of the British Association of Urological Surgeons approved courses.

International Medical Graduates (IMGs) wishing to train in urology must gain full GMC registration, as well as 12 months of post-registration experience in order to apply for CST. Requirements to gain full GMC registration include completing English language examinations, the Professional and Linguistics Assessment Board examination and an internship equivalent to FY1 [9]. IMGs from the European Economic Area (EEA) are recognized as equivalent to UK trainees, and graduation from med- ical school is sufficient for provisional registration. Following completion of an internship equivalent to FY1, they are eligible for full registration.

IMGs can alternatively apply directly to ST3 urology training. Requirements include full GMC registration, completing of the membership of RCS examination and postgraduate training that has been assessed for equivalency by the RCS. EEA graduates may apply directly for specialty training alongside UK trainees, provided they meet the same entry requirements. Non-EEA IMGs may only apply for remaining posts for which no suitable UK/ EEA applicant was found [10].

In the UK, the proportion of IMGs in urology training (ST3-7) has decreased from $31.5 \%$ in 2012 to $12.3 \%$ in 2018. This decrease has been largely non-EEA doctors, while the number of EEA doctors has remained similar. This trend is reflected overall in training pathways in the UK (including foundation, core training and specialty training) with a decrease from $20.4 \%$ of IMGs in 2012 to $15.1 \%$ in 2018 [11].

IMGs who have trained in urology abroad, and are seeking to practice as a consultant must apply to have their training reviewed for a Certificate of Eligibility for Specialist Registration [12]. This certificate is equivalent to a certificate of completion of training, and also allows candidates to apply for full GMC registration at the same time. In 2017, 15 applicants applied for a urology Certificate of Eligibility for Specialist Registration, 7 of which were successful (47\% success rate) [13].

\section{United States of America}

After completion of medical school, graduates must complete a 1-year surgical internship, followed by a 4-year urology residency in order to complete their training. As of 2019, all urology residency programs will include a 1-year internship. This internship must include 3 months of general surgery, 3 months of core surgical rotations (trauma, vascular or critical care) and 6 months of other rotations. The residency lasts 4 years, with 1 year spent as a chief resident. Trainees must also complete a specified minimum number of procedures and participate in research. Following residency, candidates can become board certified by the American Board of Urology $(\mathrm{ABU})$. This is a voluntary process, although $86 \%$ of practicing urologists are board certified [14]. Board certification requires completion of a Qualifying (Part 1) Examination and an oral Certifying (Part 2) Examination. Trainees can additionally pursue further subspecialty training in the form of a fellowship. Fellowships are becoming increasingly common, and around $60 \%$ of 
practicing urologists under the age of 45 have completed a fellowship [14]. Trainees must also acquire a licence to practice, which involves completing the United States Medical Licensing Examination (USMLE) steps 1 \& 2 (usually completed during medical school) and step 3 (usually completed during internship).

Competition is high for urology residency programs. In 2018, there were 405 applicants for 325 places [15]. Matching into a residency program requires high scores on the USMLE step 1 examination, and $89 \%$ of current urology postgraduate year 1 (PGY1) residents have above 230 (national mean 229) [16].

IMGs seeking to move to the USA for training must first become Educational Commission for Foreign Medical Graduates certified, which involves completion of the USMLE step 1 and 2 examinations. Candidates can then apply to urology residency programs through the urology match via the same process as an American graduate, although generally require higher USMLE scores and a stronger CV compared to local graduates. The success rate is much lower for IMGs $(24 \%)$ compared to US medical students $(86 \%)$. The proportion of IMGs in urology has decreased over time from $27 \%$ in 1978 to $5 \%$ in 2013 [17]. In 2019, an unusually high number of IMGs matched into urology (23, match rate 58\%) [18] compared to a historical match rate of $17-33 \%$ [15].

Canadian trained urologists can apply for $\mathrm{ABU}$ board certification, although their application is reviewed on a case-by-case basis. IMGs who have completed training in countries other than the USA or Canada must complete an Accreditation Council for Graduate Medical Education (ACGME)-approved residency, irrespective of prior experience. An alternative pathway is available for IMGs, but this is not common. IMGs who have spent 7 years at an institution with an ACGME-approved urology program, and received the rank of full professor, can apply for certification [19].

\section{Canada}

Canadian medical graduates must complete a urology residency after medical school, usually a minimum of 5 years in length. The first 2 years of residency is termed 'Surgical Foundations', where trainees acquire core surgical skills and complete the Royal College Surgical Foundations examination. Trainees then undertake 3 years of urology training, followed by the Royal College examination in urology [20]. Completion of the residency and examinations allows a trainee to become Royal College certified in urology. After residency, trainees may pursue additional fellowship training. Fellowships have

Urology Training in Five

English-Speaking Countries become increasingly popular over time, and currently $72 \%$ of Canadian residents opt to undertake one. The most common area for fellowship (39\%) was minimally invasive surgery [21].

Training requirements for surgical foundations include at least 12 weeks of urology (maximum 52), 12 weeks of general surgery and 8 weeks of critical care medicine. During the urology training, 12 weeks must include pediatric urology, and 24 weeks must be spent as a senior resident. A maximum of 12 weeks can be used as research time. Residents are also required to complete one research or educational project.

Urology has become more competitive in Canada since 2015. In 2018, there were 72 applicants for $29 \mathrm{Ca}$ nadian medical graduates urology residencies - a ratio of 2.5:1, compared to $1.5: 1$ in 2015 [22].

To apply for residency in Canada, IMGs must complete Part 1 of the Medical Council of Canada Qualifying Examination (MCCQE) as well as the National Assessment Collaboration Examination. There is also a requirement for Canadian citizenship or permanent residency. There are a fixed number of training positions available, as places are separate for Canadian medical graduates and IMGs. Generally, there have been very few positions open to IMGs over the last few years, and in 2018, there were 44 applications for just 3 urology IMG positions [22].

IMGs who have completed training elsewhere can apply through the 'approved jurisdiction route'. The UK, Australia and New Zealand all qualify as approved jurisdictions [23]. If a trainee is deemed comparable, they can become Royal College certified upon completion of the Royal College Surgical Foundations examination and the examination in urology. Candidates also require a licence to practice in a particular state. Requirements vary between states, but generally include Royal College certification, completion of the Parts 1 and 2 of the MCCQE, and Canadian citizenship or permanent residency.

\section{Australia/New Zealand}

Following completion of medical school, graduates must complete PGY1 in order to receive general registration, followed by PGY2 in order to apply to a specialty training program. Prospective urology trainees are required to meet a large number of eligibility criteria before applying, including specific clinical rotations (10 weeks of emergency medicine, 26 weeks of surgery at PGY2 or above, and 26 weeks of urology at PGY2) [24]. Additionally, candidates must complete the Royal Australasian College of Surgeons (RACS) Generic Surgical 
Sciences Examination, and from 2022, the RACS clinical examination (currently taken during training).

The urology new Surgical Education and Training (nSET) program is a 5-year program consisting of 1 year of basic urology training to acquire general surgical skills (nSET1), 2 years of intermediate training (nSET2/3) including completion of the Urology Surgical Science Examination, followed by 2 years of advanced urology training (nSET4/5) including completion of the fellowship RACS exam (FRACS). Once training is complete, doctors are awarded the FRACS in urology [25].

The core competencies, which must be achieved vary depending on stage of SET training. Generally these requirements must be met each quarter, and include supervisor reports, logbook keeping, and supervised learning events such as directly observed procedures [26].

In 2018, 19 trainees were appointed to the 2019 nSET program, however no figures were available for the total number of applicants. In 2016 there were 78 applicants for 16 places (4.9 applicants per post). In 2015 there were 96 applicants for 29 places (3.3 applicants per post). The applicant per post ratio has remained similar since 2011 [27].

IMGs applying to urology training in Australia must first gain general registration, as well as permanent residency or citizenship of Australia or New Zealand [28]. Certain countries qualify as a 'competent authority', including the UK, USA, Canada and New Zealand [29]. IMGs from these countries must have completed an internship in their home country in order to apply for provisional registration under this pathway. Upon completion of 12 months of training in Australia, candidates are awarded general registration, after which they can apply for urology training. As previously mentioned, entry into the urology nSET program requires certain rotations to be completed before applying, so it is likely that an IMG will need to undergo further PGY2 training in order to meet these requirements.

IMGs without any form of prior registration in their country of origin must apply via the standard pathway. As part of this IMGs must sit the Australian Medical Council computer adaptive test with multiple choice questions examination before applying to the board for registration.

Urologists who have completed specialist training in their country can apply via the 'specialist' pathway. The RACS assess applications for comparability with an Australian trainee. Substantially comparable candidates will be granted specialist registration after a period of up to 12 months of supervised clinical practice. Partially comparable candidates require up to 24 months of supervised practice, and must complete the urology fellowship ex- amination. Urology-specific data is not available, but the RACS received 62 applications for the specialist pathway in $2017,41(66 \%)$ of which were partially or substantially comparable.

IMGs seeking to train in the urology nSET program in New Zealand must be a permanent resident or citizen of Australia or New Zealand, and have Medical Council of New Zealand (MCNZ) registration with general scope of practice.

IMGs who have graduated from the UK, completed their FY1 and are fully GMC registered are eligible for MCNZ registration with a provisional scope of practice. General registration will be granted after 6 months of supervised practice in New Zealand [30].

IMGs from 'comparable health systems', including the USA and Canada, can apply for registration with a provisional scope if they hold full registration in their home country and have completed 33 months of training [31]. Registration with a general scope can be awarded after 12 months of supervised practice in New Zealand. IMGs who are not eligible for these pathways must pass the New Zealand Registration Examination clinical examination, and complete a 2 year intern training programme in New Zealand (although they can apply for general registration after the first year) [32]. IMGs must apply directly to MCNZ. An online approval process is carried out following submission of the necessary forms, documentation and fees. IMGs must also have permanent residency or citizenship status of Australia or New Zealand if applying for the nSET program [28].

IMGs with specialist training in another country may apply to the MCNZ via the vocational pathway [33]. The RACS assess an applicant's qualifications against the standard of a New Zealand trained urologist. If deemed comparable, in order to achieve specialist registration, candidates must either complete 6-12 months of further training (supervision pathway) or 12-18 months of further training plus assessment (assessment pathway).

\section{Discussion}

This study highlights several key similarities and differences between urology training in 5 major Englishspeaking countries, as well as the strengths and limitations of these respective systems.

Length of training varies considerably. The UK is the longest at a minimum of 9 years of postgraduate experience, compared with 7 years for Australia and New Zealand and 5 years for the USA and Canada. This has been 
attributed to the European Working Time Directive introduced in 2003, which has seen a significant reduction in average hours worked [34]. The maximum average hours mandated per week is capped at 48 hours for the UK, compared with 80 hours for the USA.

This difference in the length of training between countries is reflected in the structure of their training programs. The UK remains unique in that the program for acquisition of generic surgical skills (e.g. CST) is separate to urology, and must be completed before beginning urology training. In comparison, for other countries, acquisition of these skills is integrated into the earlier years of the urology program. This overcomes the necessity for trainees to undergo an additional application process in order to obtain a competitive training post.

The Improving Surgical Training initiative has highlighted a key issue with UK training as a poor balance between learning opportunities and service provision [6]. As a result, a 'run-through' program in urology, lasting from ST1-ST7 will be piloted in 2019. This will include exposure to general surgical skills as part of urology training, and therefore standardize UK training to that of other countries.

Research exposure is a mandatory training requirement for all countries. However, only the USA and Canada offer the option of protected research time during urology training, unlike the UK, Australia and New Zealand. It has been shown that protected research time during urology training increases research output [35]. A lack of protected research time is one potential reason why many trainees from the UK, Australia and New Zealand pursue fellowships [4]. Overall, there is a strong case for protected research time during urology training, and new training schemes should seek to include this as part of the national curriculum in order to facilitate research output during training.

Sub-specialization experience is another aspect, which varies between countries. The UK remains unique in this regard, as the only country which guarantees sub-specialty exposure as part of its training program. In Australia and New Zealand, subspecialty experience is possible, although explicit time periods are not provided. The USA and Canada offer 'elective' rotations, but this significantly varies between programs. Sub-specialty fellowship experience has increased in popularity over time, with many considering it a necessity to secure a desirable post on completion of training [4]. Therefore, it may be pertinent for countries to reinforce sub-specialty exposure into the later stages of their training.

Procedure numbers performed varies between countries. The UK, USA and Canada curricula specify a mini-

Urology Training in Five

English-Speaking Countries mum number of procedures trainees must achieve. These numbers are not specified in the Australia and New Zealand nSET curriculum. The minimum number of procedures required for UK urology trainees is greater than those for the USA. Given the longer length of training in the UK, this is to be expected. However, reports show that even with a lower expected procedure number, USA trainees are completing far more than those in the UK. For example, UK trainees reported an average of 14 robotic prostatectomies during training [36] compared with an average of 96.8 for US residents [37]. Indeed, many UK trainees are not meeting specified minimum procedure numbers, although this is yet to prevent award of a certificate of completion of training [38]. The importance of exposure to different procedures has been acknowledged universally, in the UK [34], Canada [39] and Australia [40] and this is crucial to satisfy the requirements of a competency-based curriculum. Hence, the introduction of run through urology training may be crucial to helping UK trainees achieve minimum targets.

Examinations required are comparable between different countries. All countries studied require completion of a non-urology specific examination earlier in training, followed by completion of a urology-specific examination at the end of training in order to become certified as a specialist. Furthermore, in all countries a combination of theory and practical examinations are used throughout training.

Competition for urology training posts remains high. In Australia and New Zealand the level of competition has remained fairly constant over time. However, the UK, USA and Canada have seen an increase in competition year by year. This is partly explained by an increase in the number of domestic graduates within these countries. The adverse effect of this has been a decrease in the number of IMGs applying for urology training. In the UK, the proportion of IMGs in urology posts is decreasing significantly compared to other surgical specialties. In particular, the number of non-EEA graduates has decreased, whereas the number of EEA graduates remains constant [11]. Similarly, the USA and Canada have seen a slight decline in IMG urology residents, while other surgical specialties have retained their intake [17].

The ease of moving country for urology training varies considerably. The UK is easier compared to other countries, as there is no absolute requirement for citizenship and non-EEA IMGs are only required to pass the Professional and Linguistic Assessments Board examination. Australia and New Zealand are harder locations; although there is no need for most IMGs to sit an 
additional examination (compared to local candidates), permanent residency is a requirement for the urology nSET program. The USA is regarded as more difficult, especially for competitive specialties, as IMGs need high scores on the USMLE, as well as letters of recommendations and clinical experience in a US institution. Canada poses the most challenging location for aspiring urology trainees. As well as high scores in the MCCQE, permanent residency is required and there is a specific IMG quota for urology, which ranges from just 1 to 3 places each year. The decline in IMG numbers in urology training for the UK, USA and Canada is a universal concern, especially for the USA where the supply of urologists does not match population growth [41]. Therefore, it is essential countries review their policy for IMGs, in order to remain attractive to the highest calibre of international candidates and ensure world-class standards in patient care.

To our knowledge no study as yet has provided an objective comparison of urology training across different countries. Our study offers a review of not only the train- ing structure in each country, but also the content and performance. However, we recognize that our knowledge of urology training outside the UK is limited to publicly gathered information from official governing bodies and from online resources.

\section{Conclusion}

Reform of healthcare training has become a global phenomenon. Ensuring that the UK remains amongst the world's best training programs is of the utmost importance, and this is evident following the Royal College of Surgeons Improving Surgical Training report. By comparison with other leading programs across the world, we are able to identify the optimal elements of these training programs, and incorporate them into the UK training system in order to provide the best system for trainees and patients alike.

\section{References}

1 Clayman RV, Kavoussi LR, Soper NJ, Dierks SM, Meretyk S, Darcy MD, Roemer FD, Pingleton ED: Laparoscopic nephrectomy: initial case report. J Urol 1991;146:278-282.

-2 Gettman M, Rivera M: Innovations in robotic surgery. Curr Opin Urol 2016;26:271-276.

- 3 Honda M, Morizane S, Hikita K, Takenaka A: Current status of robotic surgery in urology. Asian J Endosc Surg 2017;10:372-381.

4 Bhatt J: Urological fellowships - the unwritten but almost essential step to a future specialist consultant practice? BJUI. 2014. Available from: https://www.bjuinternational.com/ bjui-blog/urological-fellowships-the-unwritten-but-almost-essential-step-to-a-future-specialist-consultant-practice/.

5 The British Association of Urological Surgeons: Career path of a urologist, 2018.Available from: https://www.baus.org.uk/professionals/education/career_path_of_a_urologist. aspx.

6 The Royal College of Surgeons: Improving surgical training, 2018. Available from: https://www.rcseng.ac.uk/-/media/files/ rcs/.../1111_ian_regional-reps-nov-2015.pdf.

7 Higher Education England: 2018 competition ratios. Available from: https://specialtytraining.hee.nhs.uk/Portals/1/Content/Resource Bank/Competition Ratio\%27s/Competition Ratios 2018.pdf.

8 Joint Committee on Surgical Training: Certification guidelines for urology. 2017.
9 General Medical Council: Full registration for international medical graduates. 2018. Available from: https://www.gmc-uk.org/ registration-and-licensing/join-the-register/ registration-applications/application-guides/ full-registration-for-international-medicalgraduates.

10 British Medical Association: Guide for doctors new to the UK. 2019. Available from: https://www.bma.org.uk/advice/work-lifesupport/life-and-work-in-the-uk/guide-fordoctors-new-to-the-uk.

11 General Medical Council: GMC data reports. 2018. Available from: https://data.gmc-uk. org/gmcdata/home/\#/reports/Postgraduate training/Stats/report.

12 General Medical Council: Full registration. 2019. Available from: https://www.gmc-uk. org/registration-and-licensing/the-medical-register/a-guide-to-the-medical-register/ full-registration.

13 General Medical Council: CESR and CEGPR statistics 2017. Available from: https://www. gmc-uk.org/-/media/documents/sat-statistics---cesr-2017---dc10557_pdf-72202708. pdf.

14 American Urological Association: The state of the urology workforce and practice in the United States 2017. Available from: http:// www.auanet.org/common/pdf/research/census/State-Urology-Workforce-Practice-US pdf.
15 American Urological Association: Urology and specialty matches. 2018. Available from: https://www.auanet.org/education/auauniversity/for-residents/urology-and-specialty-matches.

16 Association of American Medical Colleges: USMLE Step 1 and Step 2 CK scores of firstyear residents, by specialty. 2018. Available from: https://www.aamc.org/data/493920/report-on-residents-2018-b2table.html.

17 Halpern JA, Al Hussein Al Awamlh B, Mittal S, Shoag JE, Hu JC, Lee RK: International Medical Graduate Training in urology: are we missing an opportunity? Urology 2016;95: 39-46.

18 American Urological Association: 2019 urology residency match statistics.

19 American Board of Urology: Residency requirements. 2018. Available from: http:// www.abu.org/residency-requirements/.

20 Royal College of Physicians and Surgeons of Canada: Specialty training requirements in urology. 2014.

21 Welk B, Kodama R, Macneily A: The newly graduated Canadian urologist: over-trained and underemployed? Can Urol Assoc J 2013 7:E10-15.

22 Canadian Resident Matching Service: Data and reports. 2018. Available from: https:// www.carms.ca/data-reports/r1-data-reports/. 
23 The Royal College of Physicians and Surgeons of Canada: Approved-jurisdiction route for IMGs. 2018. Available from: http://www.royalcollege.ca/rcsite/credentials-exams/exam-eligibility/assessment-imgs/approved-jurisdiction-route-international-medical-graduates-e.

24 Urological Society of Australia and New Zealand: Selection regulations surgical education and training program in urology 2020 intake. 2018. Available from: https://www. usanz.org.au/uploads/65337/ufiles/Education/SET_UROLOGY_SELECTION_REGULATIONS_2019_-_Approved.pdf.

25 Urological Society of Australia and New Zealand: SET program in urology (nSET). 2018. Available from: https://www.usanz. org.au/new-set-program-in-urology-nset/.

26 Urological Society of Australia and New Zealand: Regulations and forms. 2018. Available from: https://www.usanz.org.au/regulations-and-forms/.

27 Health Workforce New Zealand: RMO factsheets - urology. 2017. Available from: https:// www.kiwihealthjobs.com/rmo/pdf/Urology. pdf.

28 Royal Australasian College of Surgeons: Application information - applying to SET as an IMG. 2018. Available from: https://www.surgeons.org/becoming-a-surgeon/international-medical-graduates/set-application/.

29 Medical Board of Australia: Assessment pathways to registration for international medical graduates. 2018. Available from: https://www.medicalboard.gov.au/registration/international-medical-graduates.aspx.

30 Medical Council of New Zealand: Registration requirements - Option 3 competent authority pathway. 2018. Available from: https://www.mcnz.org.nz/get-registered/ scopes-of-practice/general-scope/registration-requirements/option-three/.
31 Medical Council of New Zealand: Registration requirements - Option 4 comparable health system pathway. 2018. Available from: https://www.mcnz.org.nz/get-registered/ scopes-of-practice/general-scope/registration-requirements/option-four/.

32 Medical Council of New Zealand: Registration exam - NZREX clinical. 2018. Available from: https://www.mcnz.org.nz/get-registered/registration-exam-nzrex-clinical/.

33 Medical Council of New Zealand: Types of vocational scope - urology. 2018. Available from: https://www.menz.org.nz/get-registered/scopes-of-practice/vocational-registration/types-of-vocational-scope/urology/.

34 Gohil R, Khan RS, Ahmed K, Kumar P, Challacombe B, Khan MS, Dasgupta P: Urology training: past, present and future. BJU Int 2012;109:1444-1448.

35 Andrews JM, Abdolell M, Norman RW: Canadian urology resident scholarly performance. Can Urol Assoc J 2013;7:E402-406.

36 Gill JD, Stewart LF, George NJ, Eardley I: Operative experience of urological trainees in the UK. BJU Int 2012;109:1296-1301.

37 Accreditation Council for Graduate Medical Education: Urology case logs - National Data Report. 2018. Available from: https://www. acgme.org/Portals/0/PDFs/480_National_ Report_Program_Version_2017-2018.pdf.

38 Lee E, Dyer JE, O’Flynn KJ, Terry T, Robinson R: A five-year review of operative experience and indicative numbers in urological training in the UK and Ireland. J Clin Urol 2017;10:506-512.

39 Beiko D, MacNeily AE, Robert Siemens D: Is 10000 hours enough for urology residency? Can Urol Assoc J 2016;10:9-10.
40 Pirpiris A, Chung ASJ, Rashid P: From humble beginnings ... the evolution of the FRACS (Urology). ANZ J Surg 2017;87:619-623.

41 Pruthi RS, Neuwahl S, Nielsen ME, Fraher E: Recent trends in the urology workforce in the United States. Urology 2013;82:987-993.

42 Palmer M, Taylor C: British Association of Urological Surgeons and the Specialist Advisory Committee in Urology workforce report. 2017. Available from: https://www.baus. org.uk/_userfiles/pages/files/About/Governance/2017 Workforce Report.pdf.

43 Canadian Medical Association: Urology profile. 2018. Available from: https://www.cma. $\mathrm{ca} / \mathrm{sites} / \mathrm{default} / \mathrm{files} / 2019-01 /$ urology-e.pdf.

44 Royal Australasian College of Surgeons: Surgical workforce 2016 census report. Available from: www.surgeons.org.

45 British Medical Association: Pay scales for junior doctors in England. 2019. Available from: https://www.bma.org.uk/advice/employment/ pay/juniors-pay-england.

46 Medscape: Residents salary and debt report 2017. Available from: https://www. medscape.com/slideshow/residents-salary-and-debt-report-2017-6008931\#9.

47 Canadian Resident Matching Service: Salary - CaRMS. 2018. Available from: https:// www.carms.ca/match/r-1-main-residency-match/salary/\#1511458863948-b49dfdf2-619d.

48 Australian Medical Association: Medical practitioners - AMA Agreement 2016. Available from: https://www.amawa.com. au/wp-content/ uploads/2017/08/Junior-Doctors-Information-Guide-2016-Agreement-Salary-and-Allowance-Tables-at-Back-of-Document.pdf. 